\title{
Transdermal patches: past, present and future
}

\begin{abstract}
"One of the hottest topics in transdermal delivery enhancement for the past (yikes) 15 years or so is microneedles (and other ablative technologies that remove or breach the stratum corneum) yet, there are no approved products yet."
\end{abstract}

\section{Keywords: history $\bullet$ medicated tape $\bullet$ percutaneous delivery $\bullet$ TDD $\bullet$ transdermal patch}

Whenever I speak on any topic regarding transdermal patches, I am invariably asked what the future holds. Sometimes, it seems that the audience is patiently sitting through my talk just so they can ask me that most general question.

I have spent the better part of my adult life designing transdermal patches, but solving the technical issues is only one factor in the success of such a special product. One might ask, what is so special about transdermal patches anyway? A transdermal patch is an engineered, external, continuous and long-acting dosage form. These are a lot of adjectives, so let me break that down:

- Engineered: a structure and composition that is precise, accurate and predetermined;

- External: not ingested, inhaled, implanted, inserted or injected;

- Continuous: insensitive to short half-life or narrow therapeutic window;

- Long-acting: up to a week between doses.

- There simply is no other pharmaceutical dosage form that has all of these properties, but how did it all begin?

Everybody knows that coming into contact with certain plants can cause an allergic reaction. Among these are such common irritants as poison ivy, oak and sumac [1] or the latex from the rubber tree [2]. Less wellknown culprits are the skins of many fruits including mangos [3], papayas and bananas. Even ragweed can cause an allergic reaction [4]. In fact, just typing 'dermatitis' into the US FDA's Poisonous Plant Database generates over 1000 references [5].

But such reactions are not limited to cutaneous hyperimmune responses. Prolonged occupational exposure to tobacco leaves can result in nicotine poisoning (known as 'green tobacco sickness') which was not really recognized until migrant workers began to harvest tobacco on large-scale commercial plantations in the middle of the 20th century [6].

Since many of these plants are either ubiquitous or have been cultivated for millennia, it seems reasonable to conclude that people understood the consequences of touching these plants for nearly as long. If the consequences of touching these plants were generally known, then it is not a very big logical leap to assume that there was something in these plants that was able to penetrate the skin.

A more recent example from the late 19th to early 20th century involves occupational exposure to nitroglycerin. Many workers who came in contact with nitroglycerin experienced 'Monday disease' or severe headaches and (those with underlying heart disease) also tended to have 'Sunday heart attacks' [7]. Bearing in mind that oral nitroglycerin was already being used to treat angina pectoris, folks realized pretty quickly what was happening $[8]$.

The skin is, of course, our protection from various environmental assaults. But, it is also the protective barrier that allows us to live outside the sea (were it not for the amazing

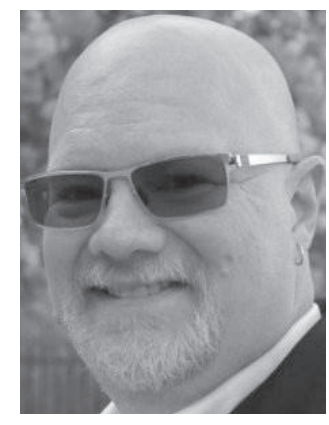

Ken Miller

ISYN Consulting, Fall River, MA (304) 376-4700, USA

doctor.ken.miller@gmail.com 
ability of our skin to hold water, we would shrivel up and die in short order).

But water does diffuse out of the skin. Despite the ability of the skin to retain water within our bodies, a small amount of water does continually escape into the environment (and it is not just sweat). This tiny flux of water usually goes unnoticed, but it can carry other chemicals with it that are easily detectable.

You may have noticed that eating or drinking certain things produces odors from the skin (often, you will notice it in someone else). For example, heavy drinking (alcohol) will give off an odor long after the party is over. You may also notice a distinctive aroma emanating from someone who has eaten large quantities of garlic, onions or certain savory spices. So, it is clear that there are also certain things that can pass through the skin from the inside.

\section{"Oddly, the idea of a nitroglycerin ointment (for angina pectoris) never really caught on."}

So, I posit that mankind knew that some things could pass through the skin, a long, long time ago. But, this was an observation, not medicine.

At some point in history, the observation that stuff can enter the skin morphed into the deliberate topical application of medicine. Most likely, the first such treatments were for local conditions (rashes, wounds, boils, hives, itching and infection, among others), but the first topical treatment used as systemic medicine may have been the mustard plaster which dates back (at least) to the ancient Greek physician Hippocrates [9]. These poultices or cataplasms were a part of standard medical treatments well into the 20th century (that is about 2500 years if you are counting).

However, the real turning point was arguably an observation I have already mentioned. Nitroglycerin went from being a dangerously unstable laboratory novelty to a practical industrial explosive (dynamite) to an oral medication (called glyceryl trinitrate to cognitively differentiate it from the explosive) to a recognized occupational contact hazard in the span of only a few decades. All that remained was for someone to infer that nitroglycerin could be intentionally delivered through the skin as a medicine and that happened around 1955 [10]. Oddly, the idea of a nitroglycerin ointment (for angina pectoris) never really caught on [11].

Despite the continuous bemoaning that there are relatively few molecules suited for transdermal administration and that new opportunities will run out in 6 months, $1-2$ years, 6 years, 10 years, or longer; that simply has not happened. In reality, the approval of transdermal products has been surprisingly constant since Transderm Scōp ${ }^{\circledR}$ (Alza Corporation, Vacaville, CA,
USA) gained approval in 1979. In fact, if anything, the cascade of transdermal patch approvals in the 1990s had more to do with economics than science: at the height of the transdermal 'boom' (1996), seven different patches gained FDA approval; but those seven products really only represented three molecules (nitroglycerin, nicotine and estradiol) and none of these were first to the party. It is not surprising that many people thought transdermal patches would fade into obscurity after that.

If one looks at the history of transdermal patch development as the discovery and identification of viable molecules, the interpretation is completely different. From the first commercial US patch (Transderm Scōp) in 1979 through the approval of BuTrans ${ }^{\circledR}$ (LTS Lohmann Therapy Systems Corp., NJ, USA) in 2010, new molecules reach the US transdermal market with incredible predictability as if regulated by a clock that ticks once every 2 years (the slope is actually 0.5343 new molecules per year from 1979 to 2010) [12]. If one extrapolates to the present, the correlation actually improves because we were slightly ahead of the historical pace when BuTrans ${ }^{\circledR}$ was approved.

So, what does the future hold for transdermal patches? We have already seen that new patches reach the US market with incredible regularity and, of course, there are generic patches too. This would suggest that we can continue to expect at least one new traditional patch approval (in the USA) every-other-year or so.

But where is the new technology and how will it affect the market? Well, there are already active delivery patches (those that use some active method to drive the drug through the skin) approved for use in the USA. The first active delivery patch was approved 20 years ago (Iontocaine ${ }^{\circledast}$ aka Numby Stuff, lidocaine and epinephrine enhanced by iontophoresis, IOMED Inc, UT USA). Unfortunately, it never really caught on and was discontinued in 2005. Similarly, Sonoprep ${ }^{\circledR}$ (lidocaine enhanced by ultrasound, Sontra Medical Inc, MA USA) was approved over 10 years ago. Unfortunately, it never really caught on either. That same year (2004) another lidocaine iontophoresis product (LidoSite ${ }^{\circledR}$, Vyteris Inc, NJ, USA) was approved. Now, LidoSite ${ }^{\circledR}$ hung around for a while, but it too ultimately faded away and was discontinued. The next active delivery product to be approved used heat to enhance delivery. Synera ${ }^{\circledR}$ (ZARS Pharma Inc, UT, USA) uses a chemical heating system to enhance the delivery of a mixture of lidocaine and tetracaine and it is still available. Lastly, Alza's long-awaited iontophoretic fentanyl patch (Ionsys ${ }^{\circledR}$ Alza Corporation, CA, USA) was approved in 2006, but only for use in the hospital.

One of the hottest topics in transdermal delivery enhancement for the past (yikes) 15 years or so 
is microneedles (and other ablative technologies that remove or breach the stratum corneum) yet, there are no approved products yet. There are many patents and certainly an abundance of convincing evidence that this route presents minimal risk to the patient, but there remains the 'ick' factor of 'needles' (the psychological stigma of intentionally ramming something sharp into your skin) even though they really are painless and pretty safe.

What do all these disappointments have in common? Fear. Fear of the unknown (or, perhaps more aptly, inertia).

There are a thousand more reasons to say a new product will fail as there are to say it will succeed. The commercial pharmaceutical business is very good at managing risk, so it might seem better to earn a few cents today by stretching the current technology than to risk a substantial (and sustained) investment on something really new. But that investment is essential in order to create a market for something that patients have never seen before.

\section{References}

1 FAQ: Pesky Rashes From Plants.

www.medicinenet.com

2 Latex Allergy. www.osha.gov/SLTC/latexallergy/

3 Weinstein S, Bassiri-Tehrani S, Cohen DE. Allergic contact dermatitis to mango flesh. Int. J. Dermatol. 43(3), 195-196 (2004).

4 "Itchy Rash Plants". http://landscaping.about.com

5 FDA Poisonous Plant Database. www.accessdata.fda.gov/scripts/plantox/index.cfm

6 Green Tobacco Sickness in Tobacco Harvesters - Kentucky (1992).

www.cdc.gov/mmwr/preview/mmwrhtml/00020119.htm
There's a lot of really interesting science out there. New discoveries about what skin really is, how its barrier works and how the body reacts to changes in that barrier, all suggest that we can and will find safe, new and better ways of getting medicine through the skin.

Those risk-takers that choose to address the fear and inertia of these new, novel unproven products will ultimately reap the spoils.

\section{Financial \& competing interests disclosure}

The editorial is written from the perspective of a commercial transdermal patch formulator and engineer. The author has participated in or overseen the development of some products, but neither the author nor ISYN Consulting have any affiliation or financial involvement with any products. The author has no other relevant affiliations or financial involvement with any organization or entity with a financial interest in or financial conflict with the subject matter or materials discussed in the manuscript apart from those disclosed.

No writing assistance was utilized in the production of this manuscript.

7 Marsh N, Marsh A. Nitroglycerin headache and nitroglycerin-induced primary headaches from 1846 and onwards: a historical overview and an update. Clin. Exp. Pharmacol. Physiol. 27(4), 313-319 (2000).

8 Murrell W. Nitro-glycerine as a remedy for angine pectoris. Heart Views 8, 117-121 (2007).

9 Hippocrates Collected Works I. www.perseus.tufts.edu

10 Davis J A, Wiesel B H. The treatment of angina pectoris with a nitroglycerin ointment. Am. J. Med. Sci. 230(3) 259-263 (1955).

11 Salem HH, Singh SP. Glyceryl trinitrate ointment in angina pectoris. Postgrad. Med. J. 55(654) 874-876 (1979).

12 Miller K J. The role and implications of QbD in the topical/transdermal drug development process. AAPS Webinar.

www.aaps.org/eLearning/Webinars 